\title{
Workflow Interdependence Analysis of Projects in Business Ecosystems
}

\author{
Anastasia Tsvetkova ${ }^{1,2}$, Kent Eriksson*1,3,4, Raymond E. Levitt ${ }^{3}$, and Kim \\ Wikstrom $^{1,2}$
}

\begin{abstract}
This article contributes to engineering project research by studying how projects relate to their surrounding context. The article presents a framework for the analysis of workflow interdependencies in a project that is situated in a business ecosystem. The analysis is used to reduce costly conflicts in the business ecosystem, and the framework shows how the project is positively impacted by the resolution of those conflicts. The framework elaborates James Thompson's notion of pooled, sequential and reciprocal interdependence and distinguishes between compatible-reciprocal and contentious-reciprocal interdependencies. The relationship between interdependence types and their corresponding coordination and governance mechanisms, originally posited for interdependence between tasks and groups within a single organization, applies equally well to interdependence types and governance mechanisms across firm boundaries within a business ecosystem. We analyze a cargo vessel development project within the short sea logistics business ecosystem to illustrate how the proposed framework can remove unproductive workflow conflicts and enhance value creation.
\end{abstract}

\section{Keywords}

interdependence, workflow, business ecosystem, project, hierarchy

\footnotetext{
${ }^{1}$ Faculty of Science and Engineering, Laboratory of Industrial Management, Åbo Akademi University, Turku, Finland, kenteri@kth.se* Corresponding author

2 PBI Research Institute, Turku, Finland

3 Global Projects Center, School of Engineering, Stanford University, Stanford, CA, USA

4 School of Architecture and the Built Environment, KTH - Royal Institute of Technology, Stockholm, Sweden
} 
achieve business goals at other units than the

\section{Introduction}

Projects are temporary organizations embedded in a context that surrounds them, and one of the big research questions in project research is how the project relates to its environment (Chinowsky, 2011; Sakhrani, Chinowsky and Taylor, 2017). This article contributes to project research as it analyses workflow interdependence in and around a project that is embedded in a business ecosystem, and it shows how the project can be improved by such analysis. The business ecosystem is a new level of analysis for organizing work, which is based on ecological and lifecycle perspectives of workflow coordination in the pursuit of business goals as a boundary condition for the organization. Business ecosystems is akin to a business version of innovation ecologies (Dougherty and Dunne, 2011; Tracey, Phillips, and Jarvis, 2011), and answers to calls for reformed organizational boundaries in project and organization research (Santos and Eisenhardt, 2005; Walsh, Meyer, and Schoonhoven, 2006; Zammuto et al., 2007).

While projects are distinct organizations, they are also dependent on their surroundings. One way to analyze this interdependence is to study how workflows within the project ties in with workflows outside the project. The analysis of workflows beyond the confines of a project has been underutilized in research, we argue. Workflow analysis is particularly relevant in mature, highly fragmented industries like shipping and construction, because the resources used, and the activities done, need to be coordinated across project and corporate boundaries to integrate the workflows (Crowston, 1997; Håkansson et al., 2009).

Our workflow analysis framework extends James Thompson's (1967) classical pooled, sequential and reciprocal workflows, and our extension is that reciprocal workflows can be either compatible, or contentious, based on the goals of the actors involved Levitt (2015). To improve the business ecosystem, the workflows in it need to be coordinated for overall systemic commercial business benefit, and this is commonly not the case, because workflows are commonly coordinated to business ecosystem unit, most commonly at the corporate or project levels.

We illustrate our framework by an analysis of a project to develop a vessel for Baltic short sea logistics. Our illustrative case is based on data gathered from interviews, observations and the study of archival sources. In the vessel project, workflows that transcend the project boundary are identified, and then analyzed using our framework of workflow interdependencies. The workflow analysis makes it clear how the project ties in with the surrounding business ecosystem. We use the knowledge about the project's workflow interdependencies with the business ecosystem to suggest improvements to the project. Workflow analysis therefore presents a project development tool at the level of the business ecosystem.

The purpose of this article is to develop a project analysis framework that uses workflow interdependence analysis in a business ecosystem to improve the project.

This article is structured so that we first describe our research approach, followed by theory and framework development, an illustrative case analysis, and concluding discussions.

\section{A Framework for Improving System Value Creation through Workflow Analysis of Business Ecosystems}

Due to globalization and increasing interaction in business, business is increasingly generated from systems of interconnected and interdependent workflows. Workflow interdependence is an integral part of projects, as system-wide workflow coordination can unlock value-creating benefits, such as complementarity in resources (Dyer and Singh, 1998), supply chain efficiencies (Zajac et al., 1993), network externalities (Katz and Shapiro, 1994), and relationship value creation (Holm et al., 1996). Efficient workflow interdependence is achieved by the appropriate coordination of interdependent workflow activities, taking into 
account that different kinds of workflows require different kinds of interdependency and coordination (Bailey, Leonardi, and Chong, 2010; Thompson, 1967).

In our analysis, we do not focus on how work is socially constructed (Barley, 1996), because this perspective is associated with social psychological changes in society. Our focus is on workflow coordination, and for that we need to characterize workflows. Early workflow analysis suggested partitioning workflows into the work operations, the knowledge involved in operations, and the materials required for operations (Fry and Slocum, 1984; Hickson, Pugh, and Pheysey, 1969). Subsequent research has developed a more holistic conceptualization of workflows, which we follow, and define them as interdependent activities, performed by actors, that use interdependent resources (Crowston, 1997).

In business ecosystems, workflows connect across multiple projects, but these workflows may not necessarily be easily aligned. The reasons being that resources may be scarce, actors may have conflicting subgoals, and certain activities may be uneconomical.

For instance, as the scale and scope of a product or service grows, there is a natural tendency for the tasks to be subdivided into smaller tasks, and for the workers who execute them to become increasingly specialized. From the earliest days of organization theory, it has been observed that this division of labor, with the resultant specialization, produces three kinds of outcomes: The expertise to perform particular subtasks becomes isolated to the local experts who perform them; each set of specialized workers develops its own terminology; and the specialized workers tend to develop local subcultures with their own parochial subgoals (Heath and Staudenmayer, 2000; Lawrence and Lorsch, 1967). This creates a need for either centralized or distributed coordination to achieve an integrated system-level outcome.

The analysis of how workflows can be coordinated with each other in a business ecosystem requires a system-wide analysis of interdependencies between actors, resources and activities in workflows. Building on previous research on workflow interdependence analysis, we elaborate Thompson's (1967) ontology of three types of interdependence to identify four kinds of interdependence: pooled interdependence, sequential interdependence, compatible-reciprocal interdependence, and contentious-reciprocal interdependence. Each of them implies different kinds of interdependence-between and among activities, resources and actors, and they therefore require different coordination mechanism. We elaborate on how these kinds of interdependence can be used in business ecosystem analysis below.

\section{Pooled Interdependence}

The simplest type of workflow involves "pooled" interdependence, in which workers accomplish a set of activities, all of which are needed to achieve the desired system-level outcome, but there are no technical or timing interdependencies between tasks. Any task required for completion has at least pooled interdependence with other tasks in the project. The system integrator of a fragmented workflow can coordinate pooled interdependence among subtasks by specifying tasks' required outputs and the activities and resources required for the workers who will carry out those tasks. Alternatively, for unskilled workers, pooled interdependence can be coordinated by specifying -and in some cases, enforcing- the detailed work process by which each task should be carried out. Unless the scope of the required system changes, workers can then complete their tasks relatively independently of the system integrator or other workers, because there are no technical or timing interdependencies between tasks.

Pooled interdependence is the least costly form of interdependence to coordinate. Mature industries evolve highly standardized and institutionalized manufacturing processes that define standard component functions and subsystem interfaces, making coordination a matter of matching standard components.

\section{Sequential Interdependence}

If a given task that already has pooled interdependence with all other tasks in the project faces the additional constraint that it cannot be initiated until one or more prerequisite tasks have been partially or fully completed, the two or more 
involved tasks exhibit "sequential" interdependence as well as pooled interdependence. Sequential interdependence arises from physical, topological or shared resource constraints, so that the involved activities need to be executed in a sequential manner-for example, in conventional manufacturing and assembly or construction.

A system integrator can coordinate sequential interdependence centrally by: (1) scheduling tasks to occur in a specified sequence and requiring them to be completed by specified times, and (2) rescheduling tasks as needed to accommodate variance in the completion of prerequisite tasks or shortfalls in the availability of required shared resources. Inserting buffers between tasks that have high variance in their durations is a commonly used strategy to avoid the need for frequent rescheduling (Goldratt, 1997).

\section{Reciprocal Interdependence}

The third type of workflow defined by Thompson involves "reciprocal" interdependence between two or more subtasks. Thompson stated that coordination of this type of interdependence requires "mutual adjustment" between the interdependent parties, but did not clearly explain how it arises or what would be required to assure that decentralized mutual adjustment occurs effectively and reliably. Thus his definition of interdependence and its required form of coordination is somewhat tautological; this has spurred researchers to consider alternative conceptualizations.

Many of these researchers identify reciprocal interdependence as being subdivided in two, where one is without conflicts between the integrating actors, and the other contains conflicts (Aalst, 2000; Barki and Pinsonneault, 2005; Saavedra, Earley, and Van Dyne, 1993; Vegt and Vliert, 2002). Following Levitt (2015), we note that reciprocal interdependence can take two forms"compatible" vs. "contentious"- each requiring additional governance mechanisms to foster mutual adjustment in ways that optimize system level performance while minimizing the need to escalate decisions to the system integrator in case of an impasse.
- "Compatible-reciprocal" interdependence requires mutual adjustment to achieve a spatial or functional fit between the task outputs of the interdependent workers; however, achieving mutual adjustment to obtain the fit does not invoke conflicting sets of subgoals for the involved actors. Compatible-reciprocal interdependence can thus be governed simply by requiring that frequent communication and confirmation occur between the involved actors, initially in choosing, and subsequently if and when revising, each of their detailed component specifications in order to maintain alignment between their respective components or subsystems.

- In contrast, "contentious-reciprocal" interdependence also requires mutual adjustment to achieve a spatial or functional fit between the outputs of the interdependent workers' tasks; however, achieving alignment now invokes conflict between one or more of the subgoals held by each worker - i.e., a given choice of the output that is more desirable to one is less desirable to the other, and vice versa.

An example of contentious-reciprocal type of workflow is the design of an automobile door, for which the safety engineer prefers a heavy, reinforced steel door to protect the occupants from a side-impact, while the mechanical engineer designing the engine prefers the lightest possible door-an aluminum alloy door-to optimize acceleration and fuel consumption. In turn, the manufacturing engineer might prefer a lightweight steel door, which is easier to press and paint than an aluminum alloy door, but less safe than a heavy, reinforced steel door. For workflow with this kind of contentious-reciprocal interdependence, there is a conflict between subgoals, which hinders the achievement of mutual adjustment. For the reciprocal workflow to be performed, there has to be a resolution to the contentious subgoals. Two models are prominent: one where the actors voluntarily subscribe to overarching system-wide goal, and one where an overarching hierarchy needs to be enforced.

First, an example of voluntary governance: If the actors in our automobile example have been 
acculturated to understand the trade-offs between safety, acceleration/fuel economy and ease of manufacturing, they are likely to be able to set aside their subgoals in favor of the system wide goals. They will reach a mutually acceptable and system-level effective compromise in spite of having different subgoals. Even though their subgoals are conflicting, they achieve selforganized mutual adjustment (Ostrom, 1990).

Next, an example of hierarchical governance: If one or more of the actors in the automobile door example hews to their own discipline's or business unit's parochial subgoals, the interdependent parties will likely reach an impasse in negotiation and fail to achieve mutual adjustment. This impasse will require them to escalate the issue to a more senior manager, or systems integrator with a more global perspective on the trade-offs to make the decision and resolve the impasse.

Whether voluntary or involuntary, contentious-reciprocal interdependence is the most complex and costly kind of interdependence to coordinate. The cost comes from that governance of the specialized set of workers or supply chain partners in a complex and innovative crossdisciplinary project or business ecosystem is thus required to facilitate "decentralized mutual adjustment" effectively and efficiently without the need to escalate impasses. Developing evaluation criteria and rewards or contracts for supply chain actors that share risks and rewards at the system level incentivizes and enables higher order goal alignment between interdependent subteams or firms that have contentious-reciprocal interdependence based on conflicts between their parochial subgoals.

\section{Workflow Interdependencies in a Business Ecosystem}

There are multiple workflows in a business ecosystem, and they may exist for longer or shorter time periods, depending on the need for work to be executed. Workflows in a business ecosystem may not always be of direct relevance to a project in the ecosystem, because the project's work may not necessarily be dependent on all workflows in the ecosystem. However, due to the systemic properties of a business ecosystem, there are direct or indirect dependence between workflows in the ecosystem and the project. The workflows in an ecosystem and a project are depicted in Figure 1. The pooled workflows are single arrows, and sequential workflows are multiple arrows in sequence. The reciprocal compatible workflows have smileys and a handshake to symbolize goal compatibility. The contentious reciprocal

Figure 1: A Business ecosystem project in a business ecosystem

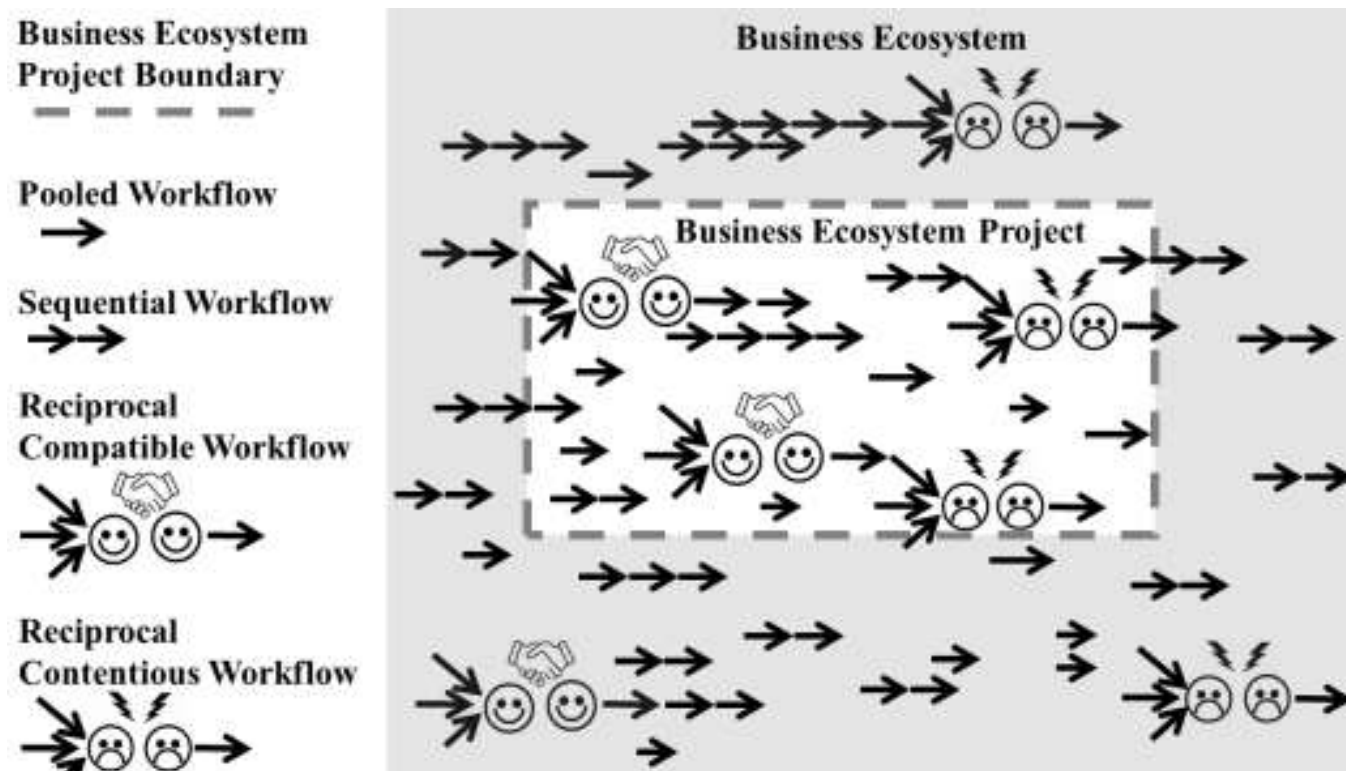

The Engineering Project Organization Journal

(C)2019 Engineering Project Organization Society www.epossociety.org 
workflows have angry faces and lightning to symbolize contentious goals.

Interdependencies among workflows in business ecosystems may change over the lifecycle of both the business ecosystem and the project. Boundaries around the business ecosystem project are permeable because the project workflows depend on those of the ecosystem to varying degree over the lifecycle of the project. Workflows become relevant to the project as they become necessary for project work over the lifecycle of the project.

\section{Coordination of Workflow Interdependence in a Business Ecosystem}

Analysis of the workflow interdependence in a project, and its surrounding business ecosystem serves the purpose of identifying what coordination mechanisms need be implemented within the project, and at the project's boundaries to the business ecosystem. In the past, researchers suggested strict deterministic relationships between workflow interdependencies and coordination mechanisms. Thompson (1967) himself identified standardization, planning, and mutual adjustment as coordination mechanisms for the management of pooled, sequential and reciprocal workflow interdependence. Recent research and practice suggests that the relationship between workflow interdependence and coordination may not be strictly deterministic, because there may be several ways to coordinate activities to achieve the same outcome. For instance, the high tech sector continuously seeks new ways of coordinating workflows, an example being a highly modular approach, which requires standardization of workflows (Sanchez and Mahoney, 1996), or empowerment of work groups to manage their work more autonomously and independently (Conger and Kanungo, 1988). We contend that workflow interdependencies limit the repertoire of coordination mechanisms available to choose from.

The relationship between workflow interdependence and coordination can be illustrated by the example of product design, which can be achieved using a modular production technique, where parts of the workflow are done separately. But the workflow requires an overarching hierarchical governance structure that coordinates the modules towards a coherent product design (Sanchez and Mahoney, 1996). The benefits of system-wide workflow integration is shown in increased knowledge exchange in production (Dyer and Nobeoka, 2000), and increased ability to innovate through the combination of complementary resources (Stieglitz and Heine, 2007). Consequently, the analysis of which coordination mechanism to choose is a matter of the interdependence of workflows in the business ecosystems.

\section{Coordination, Workflow Interdependence, and Governance of Projects in the Business Ecosystem}

The example of product design illustrates the need for governance of coordination and workflows. There is a need for overarching governance of the business ecosystem, for instance in the form of a market, hierarchy within an organization, or hybrid organization. Governance is guided by the key premise that different types of critical interdependencies-pooled, sequential, reciprocal-are often not governed optimally with respect to the business ecosystem (Larsson and Bowen, 1989). The heuristic we propose for business ecosystem optimization is to identify costly misalignments between workflows and business systems, and then to propose coordination that can improve those misalignments. The heuristic of incremental improvement of workflow by focusing on costly problems is a development of a similar heuristic that has proven useful for business process improvement (Smith and Eppinger, 1997; Sosa, Eppinger, and Rowles, 2004; Tripathy and Eppinger, 2013). We do not claim a heuristic for the identification of the most costly workflow misalignment, because that is a too complex problem to solve. We do claim that identification and resolution of workflows that conflict with business ecosystem goals will improve the business ecosystem. Our heuristic thereby strives for systemic optimization of the workflows in the business ecosystem, and the optimization is done by incremental improvements 
of the system based on observed cost. The heuristic we present can be described as pragmatist realist and incremental, since it acknowledges that workflow analysis in a business ecosystem is so complex that it is difficult to optimize, but that improvements by workflow integration in the system result in improved business ecosystem efficiency and competitiveness.

To develop a hierarchy of which workflow interdependencies are most costly, we follow Thompson (1967), who suggests that the coordination cost for reciprocal interdependencies are the highest, followed by sequential, and then pooled. We identify contentious reciprocal workflow interdependencies as incurring higher coordination costs than contentious reciprocal workflow interdependencies. Addressing the costliest workflow interdependencies thus means a that the analysis should focus:

1. Contentious-reciprocal workflow interdependence

2. Compatible-reciprocal workflow interdependence

3. Sequential workflow interdependence

4. Pooled workflow interdependence

We suggest that reducing the costliest workflow interdependencies can also be explained as eliminating 'broken agency' across phases over the lifecycle of a business ecosystem (Henisz, Levitt, and Scott, 2012). The 'broken agency' problem is simply that some firms in the business ecosystem may not want to change for the greater good of the system, and we see the same kind of broken agency, but in coordination of workflows for the greater good of the business ecosystem. A summary is provided in Table 1, where type of interdependence is on the vertical axis (Thompson, 1967), and the description of the interdependence, and coordination mechanisms are on the horizontal axis (Levitt, 2015).

\section{Research Approach}

The research process behind this article is based on clinical inquiry. Clinical research originates from the research tradition of action research and implies engaging in solving problems that are relevant to the industry (Coget, 2009; Coghlan, 2000; Schein, 1993, 1995, 2008; Schön, 1995). In this mode of research, the researchers help companies to diagnose and solve problems. Thus, the main aims of clinical inquiry include solving a clinical problem and triggering organizational change (Schein, 1995). Clinical inquiry is similar to methods such as action research and engaged scholarship, but is different in that clinical research selects a phenomenon that the actors want to develop, and that they see as important to develop. The main feature of such an approach is that tight cooperation with business actors occurs throughout the process and is iterative. The reason for choosing this approach was that the study objects, the workflows and the private and public actors in the business ecosystem, have much knowledge of their work, and can participate in analysis of their work. It allows for better access to data and constant validation of research results with the practitioners (Coghlan, 2011).

Clinical inquiry is suitable for the present research because it is suited to study emergence of social phenomena. Understanding how the workflows, project boundaries, and ecosystem context emerge, or are created over the lifecycle of a project would require the researcher to take part in the project, because data cannot accurately be collected retrospectively.

The framework proposed in this article has been developed based on both conceptual and empirical work. The researchers have been involved in an ongoing project that aims to analyze the short sea logistics business ecosystem in the Baltic Sea and, together with practitioners, develop solutions for increasing its efficiency and sustainability. The project participants included two shipping companies, two key technology providers for vessels, a shipyard, and three cargo owners. A contract was signed between a number of universities, industrial companies and a financing research-oriented company, whose shareholders are a cluster of industrial companies, and which financed the project. The contract stipulated the commitments, work, and conflict resolution in the project. Industrial companies did not provide monetary resources, but instead put the time used by staff as a commitment. On 
Table 1 Workflow interdependencies and mechanisms for their coordination and governance

\begin{tabular}{|c|c|c|c|}
\hline $\begin{array}{l}\text { Type of } \\
\text { workflow }\end{array}$ & Workflow interdependence & $\begin{array}{l}\text { Coordination } \\
\text { mechanisms }\end{array}$ & Governance mechanisms \\
\hline $\begin{array}{l}\text { Pooled } \\
\text { workflow }\end{array}$ & $\begin{array}{l}\text { Workflow activities and resources } \\
\text { are used independently of other } \\
\text { workflow activities and resources. } \\
\text { All activities aim to achieve } \\
\text { desired outcomes. } \\
\text { There are no technical or timing } \\
\text { dependencies between activities } \\
\text { and resources. }\end{array}$ & $\begin{array}{lr}\text { Coordination } & \text { is } \\
\text { achieved } & \text { by } \\
\text { specifying required } \\
\text { outputs and } & \text { skills } \\
\text { required for } & \text { work } \\
\text { tasks, or } & \text { by } \\
\text { specifying } & \text { work } \\
\text { processes. } & \\
\end{array}$ & $\begin{array}{l}\text { Governance is achieved by specifying and tracking subsystem/component } \\
\text { deliverables and quality requirements (and actor qualifications, if needed), and then } \\
\text { verifying that the requirements have been met. } \\
\text { Configuration Management processes and tools maintain records of the evolving } \\
\text { detailed specifications for all subsystems that can be verified and certified. }\end{array}$ \\
\hline $\begin{array}{l}\text { Sequential } \\
\text { workflow }\end{array}$ & $\begin{array}{l}\text { Workflow activities and resource } \\
\text { used can only be done or } \\
\text { completed following the } \\
\text { completion of other activities } \\
\text { and/or resources used. }\end{array}$ & $\begin{array}{lr}\text { Coordination } & \text { is } \\
\text { achieved } & \text { by } \\
\text { scheduling } & \text { and } \\
\text { planning. } & \end{array}$ & $\begin{array}{l}\text { Centralized governance of scheduling, and rescheduling to accommodate changes in } \\
\text { scope or variance in delivery times, is carried out hierarchically by a system integrator } \\
\text { that is at least one level in the above the interdependent actors in the project team or } \\
\text { contractual hierarchy of the business ecosystem. } \\
\text { If actors are empowered, self-synchronized, decentralized governance can be } \\
\text { deployed in which actors negotiate with one another to trade durations and start times } \\
\text { to accommodate variance (Kim and Paulson, 2003). }\end{array}$ \\
\hline $\begin{array}{l}\text { Reciprocal } \\
\text { workflow } \\
\text {-compatible } \\
\text { vs. } \\
\text { contentious }\end{array}$ & $\begin{array}{l}\text { Outputs of workers must "fit"- } \\
\text { spatially or functionally- the } \\
\text { output of other workers in one or } \\
\text { more dimensions. }\end{array}$ & $\begin{array}{l}\text { Coordination is } \\
\text { achieved by } \\
\text { frequent } \\
\text { information sharing } \\
\text { between the } \\
\text { interdependent } \\
\text { actors and rigorous } \\
\text { tracking and } \\
\text { communication of } \\
\text { changes to their } \\
\text { outputs made by } \\
\text { any of the involved } \\
\text { workers. }\end{array}$ & $\begin{array}{l}\text { Governance of compatible-reciprocal interdependence, when there are no contentious } \\
\text { subgoals among actors, requires ensuring that the involved parties share information } \\
\text { when initial design decisions are being made and any time that subsystem } \\
\text { specifications change. Configuration management processes and tools can be used to } \\
\text { formalize and impose rigor on this information sharing and updating process for both } \\
\text { compatible and contentious-reciprocal interdependence. } \\
\text { Governance of contentious-reciprocal interdependence, when actors have conflicting } \\
\text { subgoals, is intended to ensure that the involved actors negotiate to make tradeoffs } \\
\text { among their conflicting subgoals in ways that optimize system-level outcomes, rather } \\
\text { than parochial subgoals. Governance of this kind of interdependence is the most } \\
\text { challenging and nuanced. System integrators must develop a shared project identity } \\
\text { in the team; constantly communicate high level goals to participants; and, when issues } \\
\text { escalate due to impasses in negotiations, "teach the involved actors how to decide," } \\
\text { rather than "telling them what to do." }\end{array}$ \\
\hline
\end{tabular}


researchers' side, the project involved the equivalent of 6 full-time researchers per annum.

The clinical research focused on the development of business with industry actors, and used meetings and documentation as tools to bring the business development process forward. Researchers used three kinds of meetings to drive the agenda forward together with the corporations:

- Annual meetings were used to discuss the achievements during the year, and to lay out the goals for the future. Annual positioning reports lay out future work and a common vision for the project participants.

- Monthly meetings followed up the previous month's work, and planned work for the month ahead. Input to the work consisted of minutes from the previous month, and an agenda for discussions.

- Operative meetings were held with one or more corporations to address matters of operative importance. Operative meetings frequently happened on a weekly basis.

In addition to project meetings there were a number of workshops and discussions that involved not only project participants, but also companies outside the project.

The actors and the number of interactions with them are listed in Table 2.

During the project, the challenges related to the current short sea logistics ecosystem and the way vessel developments are traditionally governed were identified through these extensive discussions. After confronting the challenges thus discovered with theoretical insights regarding business ecosystems, network studies, and project management, we developed the initial conceptual framework. We used this framework for in-depth analysis of the focal short sea logistics case, and refined it based on the findings of empirical analysis, as presented in in the last chapter.

Table 2: Major communications with industry representatives during the project

\begin{tabular}{|c|c|c|c|}
\hline Actor type & $\begin{array}{l}\text { Number of } \\
\text { companies }\end{array}$ & $\begin{array}{l}\text { Total number of } \\
\text { individual } \\
\text { interviews and } \\
\text { discussions with } \\
\text { researchers }\end{array}$ & $\begin{array}{l}\text { Total number of } \\
\text { participation in } \\
\text { joint workshops }\end{array}$ \\
\hline Companies working in the project & 8 & More than 150 & More than 25 \\
\hline Cargo owners & 7 & 13 & 12 \\
\hline Ship agencies & 1 & 1 & \\
\hline Cargo brokers & 2 & 2 & \\
\hline Ship pool operators & 1 & 1 & \\
\hline Port management companies & 12 & 12 & 1 \\
\hline Stevedoring companies & 3 & 3 & 1 \\
\hline Ship operators & 2 & 5 & \\
\hline Ship owners & 2 & 5 & \\
\hline Technology (ship systems) providers & 3 & 6 & 2 \\
\hline Policy-makers & 5 & 10 & 1 \\
\hline Financiers & 3 & 6 & 1 \\
\hline IT solution providers & 1 & 1 & \\
\hline Labor union for port workers & 1 & 2 & \\
\hline Various marine associations & 1 & 1 & \\
\hline Various marine experts & 8 & 8 & 5 \\
\hline TOTAL & 60 & More than 226 & More than 48 \\
\hline
\end{tabular}


The governance models were designed and approved as the project continued partly based on theoretical presuppositions described in this article, and partly based on business viability. Thus, they were continuously tested and verified. A number of governance models proposed in this article are already being implemented, while others are still being developed conceptually within the ongoing clinical inquiry.

\section{Case Analysis}

Our analysis of the illustrative case of a vessel development in the Baltic short sea shipping ecosystem offers an example of how the success and functionality of a development is highly dependent on the surrounding business ecosystem. The current short sea logistics ecosystem in the Baltic Sea is characterized by a number of inefficiencies that make shipping-and consequently operation of vessels-economically and environmentally infeasible. Several lock-ins and even monopolies have been detected in the existing ecosystem. The utilization rate of the ships based on cargo space utilization and the amount of idle time in ports is below $40 \%$. The number of organizations involved has increased gradually and now numbers from 16-19, causing higher cost and fragmented information flow. At the same time, the shipbuilding process exhibits broken agency: it is heavily biased toward a "low-cost-oriented" logic, creating impediments for designing and delivering vessels that would be somewhat costlier to build, but would produce much greater benefits during operations over their lifecycle.

In the analysis, we focus on the most critical workflow interdependencies that were identified during the research project as the main nodes of inefficiencies in the focal business ecosystem. They span over the lifecycle of vessel and across the different parts of the business ecosystem, including the actual vessel delivery and operations, port operations and the relevant activities performed by export industry, i.e. cargo owners. Following the framework proposed in this article, eight critical workflow interdependencies are described and analyzed in the order of the

Figure 2: Mapping of critical interdependencies in business ecosystem structure in relation to the vessel investment.

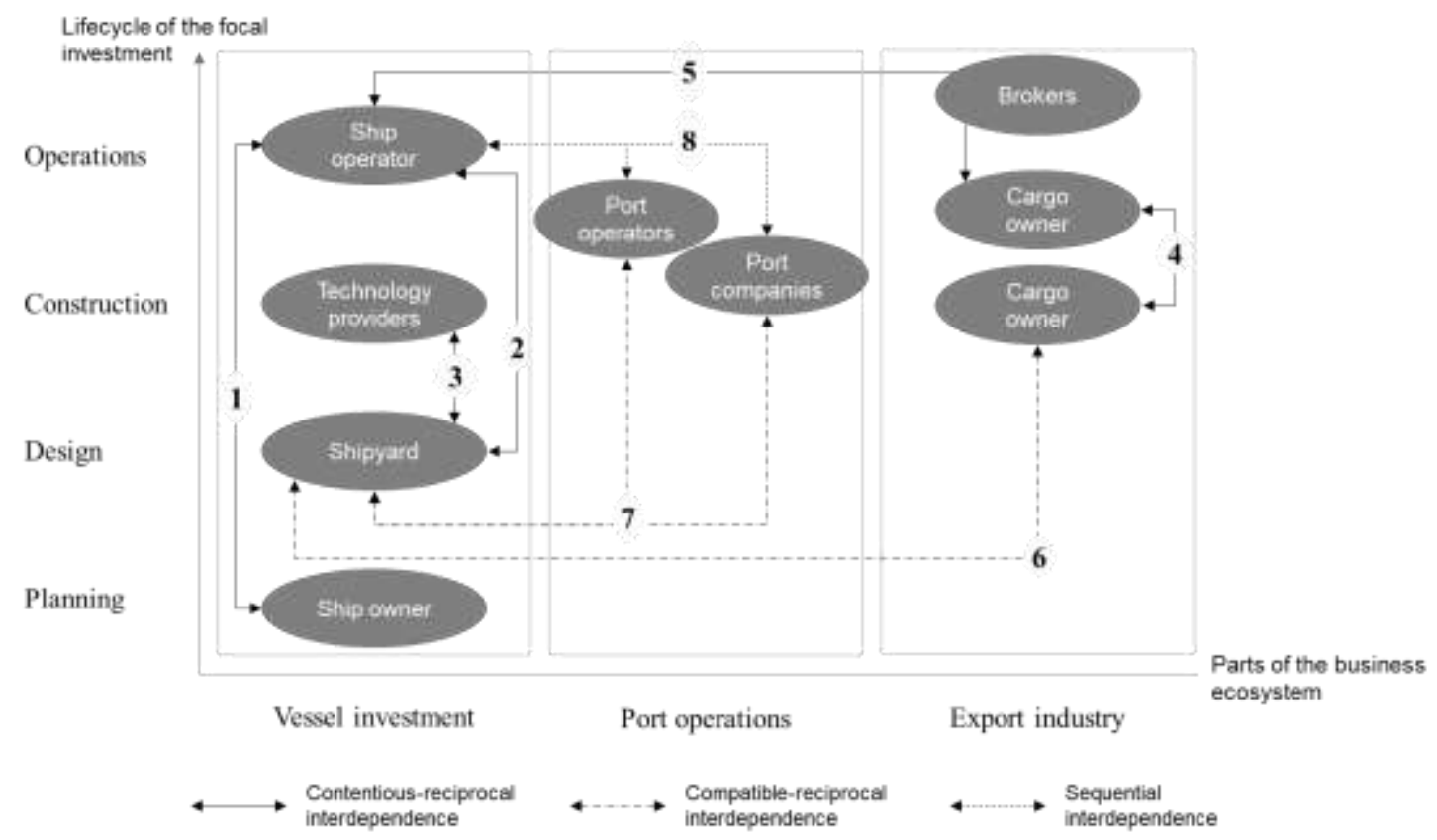

The Engineering Project Organization Journal (C)2019 Engineering Project Organization Society www.epossociety.org 
complexity of required governance - from the costliest contentious-reciprocal ones to sequential one (see Figure 2). We ignored pooled interdependencies in this analysis, because they are straightforward to coordinate with rules and standards for each of the elements of the business ecosystem.

\section{Contentious-Reciprocal Interdependencies}

The most challenging workflow interdependencies proved to be the costliest, contentious-reciprocal ones. There were five such interdependencies identified, and they were characterized by a misalignment of interests and goals of various actors in the business ecosystem. Three of them concerned the disintegration of activities during the lifecycle of vessel delivery, while two of them were related to the lack of alignment of vessel delivery and operation with the activities of the export industry, i.e. the cargo owners.

The vessel development is controlled and affected by different actors at various stages of its lifecycle. The shipowner is the actor that makes the decision about key characteristics of the vessel during the design and planning phase, such as its size, tonnage and suitability for certain cargos, while the ship operator is the one that operates the vessel during its operations phase (workflow interdependence 1 in Figure 1). Often the two actors are connected by a rather transactional timecharter party agreement, which allows a ship operator to charter and use the vessel of the shipowner for a certain price, and during a fixed period of time. In this situation, the information about actual operations is not communicated back to the shipowner, no "feedback for design" is generated either, and thus the activity of defining future ship specifications is not connected to the activity of operating vessels. Since the shipowner is not involved in, nor directly benefits from, the operations of the vessel, there is no motivation for the shipowner to invest in more advanced and potentially more expensive technology that could lead to greater lifecycle benefits, such as reduced fuel consumption, decreased costs of cargo, lower cleaning costs during operations, and timely vessel maintenance to reduce operating time lost due to downtime. The shipowner, instead, focuses on minimizing the capital expenditure related to the vessel development.

Currently, the dependency is governed as sequential by excluding the ship operator from the planning phase. Moreover, the transactional time charter contract between shipowner and ship operator does not facilitate resolving conflicting subgoals of actors in the value chain.

Further vertical fragmentation along the vessel lifecycle is caused by the highly cost-oriented business model of a shipyard, which is a technical integrator and the major actor in designing the vessel. The shipyard strives to reuse existing designs and take bids for the lowest construction cost among a multitude of technology providers; the ship operator is not involved in the design process (workflow interdependence 2 in Figure 2). A related problem is the lack of a link between the technological knowledge of various technology providers to the design and planning process (workflow interdependence 3 in Figure 2). Due to the lowest-cost-oriented bidding, there is no forum for proposing more advanced designs by technology providers, even if they have the requisite knowledge.

In all these cases, the contentious-reciprocal interdependencies are currently governed as sequential through excluding the technology providers and ship operator from the decisionmaking during the vessel planning phase and exercising a highly structured and formalized bidding process. Thus, the need for mutual adjustment is ignored, and the potential for achieving lifecycle benefits of vessel delivery and operation is overlooked. In order to unleash the potential for increased lifecycle performance of the vessel, there is a need to address, rather than avoid, the contentious nature of dependency between the activities of the named actors and move them into a concurrent co-design mode.

One solution designed during this research project was to create an alliance that would virtually integrate the actors that are critical during the lifecycle of a vessel-, virtually integrate the firms through alliance contracting, rather than integrating them legally through mergers and acquisitions. This could take place using forms of contracting that align the actors' interests and incentivize them to invest their best knowledge and 
resources in: (1) creating a vessel that would have the potential to achieve greater lifecycle performance, and (2) ensuring that the vessel would operate in the intended manner. Such actors would include the ship operator, the yard, and key technology providers. The alliance would be responsible for the design and construction of the vessel, on one hand, and for the operation and maintenance of the vessel, on the other hand.

By sharing the profit generated during lifecycle vessel operation, the participants should be motivated in a number of new and more globally optimal ways. Technology providers are incentivized to adjust the capital expenditure for a vessel based on a value-driven rather than costdriven logic, and to use their best knowledge to design and maintain the vessel in such a way that operations are not disrupted. Ship operators are incentivized to utilize their knowledge to provide input for the design of the vessel based on lifecycle operating costs given current prices, rather than being driven purely by minimizing first cost. With this combined input, designers can simulate vessel construction and operations to help align the planning activities of a number of crucial actors within the alliance, as well as with potential consumers of logistics services.

The other set of contentious-reciprocal interdependencies concerns vessel operation and the operations of cargo owners. Currently, cargo owners are reluctant to combine their bulk cargo shipments with others, due to the assumed and real quality risks and prospective schedule delays (workflow interdependence 4 in Figure 2). Our research identified the potential of introducing new cargo handling technology on the vessel, which would address the conflicting interests of various cargo owners. The opportunity to safely separate different types of cargo and efficiently combine different cargos on different routes would resolve the contentious character of this interdependence and allow for increased vessel utilization while still delivering greater value to the end customers.

Coordination can be further facilitated by a new technology - an electronic marketplace for cargo transport. This solution would also address the existing lack of efficient governance of the contentious-reciprocal interdependence between cargo owners and ship operators, which is currently bridged by cargo brokers in a somewhat opaque and non-optimal manner (workflow interdependence 5 in Figure 2). Cargo owners are interested in lower freight rates and suitable delivery schedules, while ship operator is interested in higher freight rates and high vessel utilization. Brokers, who act as intermediaries, exploit the opacity of information flow between cargo owners and ship operators and do not facilitate efficient utilization of vessels or efficient transportation of cargo. Framework suggests that this dependency could be governed as contentiousreciprocal, resolving the conflict between parties through the introduction and use of an electronic market place for cargo that enables more transparent information exchange and sets optimum freight rates. Also, more long-term contracts between cargo owners and ship operators can facilitate advanced logistics planning. By turning the interdependency into a compatiblereciprocal one, system-level optimization of cargo flows and efficient value chain can be achieved.

\section{Compatible-Reciprocal Interdependencies}

The next type of critical interdependencies analyzed are compatible-reciprocal ones. These include the interdependence between the vessel design and cargo transportation at the export industry end as well as between vessel design and design of port facilities and equipment in shipping operations. In both cases there is a natural need for compatibility between the vessel and the cargo it is intended to transport, as well as for efficient vesselport systems.

Cargo owners are the ultimate users of logistics services. Thus, vessel operations need to be compatible with industrial operations, including type of cargo transported, transportation costs, frequency, and routes. Already during the design phase, it is crucial to identify operating profiles in order to design a vessel that would show good performance during its lifecycle (workflow interdependence 6 in Figure 2). In order to do so, vessel designers need information on cargo flows during the planning stage. Although there are occasional informal discussions between shipowners and prospective end users - the cargo owners - there is no persistent dialogue between them, nor any one-time communication when the 
vessel is designed. Based on the findings, the dependency needs to be governed through early and extensive information exchange to enable the best fit of the vessel for the kinds of cargo to be transported. To achieve this, cargo owners can be incentivized to provide their input to vessel design in exchange for improved quality of transportation. As a result, the project can ensure compatibility between cargo and vessels, and that the potential for system innovation can be realized.

The other compatible-reciprocal interdependence is the dependence of vessel operations on the activities in ports and on port facilities and equipment (workflow interdependence 7 in Figure 2). There is a direct technological link between the vessel and port facilities and equipment in terms of, for example, the size of vessels that are allowed to load or unload at a given port's quay, the capacity of cargo handling facilities in the port, the compatibility of cargo handling systems on the vessel with those at the port for different kinds of cargo, etc.

Currently, the interdependence is governed as sequential. That is, port facilities and equipment are seen as a given and as a constraint for vessel design. Since, in fact, such interdependence is compatible-reciprocal, there is a need for more proactive governance, which would enable coordination between the design of the vessel and the properties of equipment and facilities in relevant ports. This can be achieved by adjusting vessel design to fit the relevant characteristics of ports at which it is likely to pick up or deliver cargo (the current, sequential governance approach), or by jointly designing vessel-port solutions. One of the solutions proposed within the project is to develop a specific technology for separating, storing, and transporting cargo on vessels, which would potentially require a different cargo handling process in ports. This would ultimately create benefits for the port owners and operators through higher throughput in ports and improved quality of their service. Although this requires a system-wide shift and naturally brings uncertainty, the attempt to achieve better technological alignment between vessels and ports can spur more intensive information exchange and workflow alignment as well.

The interdependencies spanning the boundaries of other subsystems in the business ecosystem usually require compatibility of those systems and open avenues for system innovation and network externalities. Proper governance mechanisms for such compatible-reciprocal interdependencies should support extensive, transparent information sharing and thereby facilitate mutual adjustment for optimal outcomes at the ecosystem level. A remaining key challenge is to identify mechanisms that would incentivize the actors that are currently outside the boundaries of the project to engage in transparent communication and information sharing.

\section{Sequential Interdependencies}

The last workflow interdependence is a sequential interdependence between vessel operation and port operations (workflow interdependence 8 in Figure 2). Currently, the system for managing vessel arrivals at ports significantly undermines the value creation potential of a vessel. For example, the complicated reporting and notification procedures combined with the highly inflexible working times of port operators such as stevedoring companies, force vessels to spend significant time idling in ports, while not generating any profit. In addition to that, the current "first come first served" principle creates the incentive to increase sailing speed when approaching ports, which increases fuel consumption and therefore the economic and environmental costs of operating a vessel. The relationship between ship operators and ports is transactional, and the processes at ports are highly institutionalized, making it extremely challenging to alter the current ways of working.

The dependency needs to be governed through real-time, collaborative decentralized scheduling, which includes transparent and extensive information flow in order to enable planning and just-in-time operations, parallelization of activities, such as notification of arrival, enabled by ICT technology, and negotiations among multiple ships and port about timing and sequencing of loading and unloading. Negotiations between vessels contending for port slots to purchase each other's port slots can be introduced, as described in Kim and Paulson (2003). As a result, a more efficient value chain and 'just-in-time' operations can be achieved for the benefit of the involved parties. 


\section{Summary of Workflow Interdependence Analysis in the Business Ecosystem of Short Sea Shipping}

We have identified which workflow interdependencies affect the value created by the vessel development project and analyzed how the governance of interdependencies between respective workflows needs to be adjusted. One of our major findings is that value creation is being hindered by ignoring the contentious-reciprocal character of some interdependencies. This reduces ecosystem efficiency and functionality of a given development. New governance structures and systems that address the contentious character of existing interdependencies and create a shared interest for, and information exchange among, the crucial actors in the value chain can enhance the lifecycle performance of the overall business ecosystem and each of its components.

\section{Discussion and Conclusions}

This article has developed a framework for the workflow analysis of business ecosystems. The contribution is that micro-level workflow analysis guides the governance of coordination in the business ecosystem. We identify that pooled interdependence is coordinated primarily by standardization, and governed by decentralization (Table 3). We further identify that it is the least costly coordination mechanism. Sequential workflow interdependence is coordinated by planning and scheduling, and governed by hierarchy. Sequential workflow interdependence is the second least costly to coordinate, and generates value primarily through workflow sequence optimization by prioritizing high-value tasks and eliminating idle time.

Compatible-reciprocal workflow interdependence is coordinated primarily by mutual adjustment through information sharing, self-organized relationships and networks. The

Table 3: Business ecosystem governance framework.

\begin{tabular}{|c|c|c|c|}
\hline $\begin{array}{l}\text { Type of } \\
\text { workflow } \\
\text { interdependence }\end{array}$ & $\begin{array}{l}\text { Primary workflow } \\
\text { coordination mechanism }\end{array}$ & $\begin{array}{lr}\text { Primary } & \text { business } \\
\text { ecosystem } & \text { governance } \\
\text { mechanism } & \end{array}$ & $\begin{array}{l}\text { Cost of } \\
\text { coordination }\end{array}$ \\
\hline Pooled & Standardization & Decentralization & Lowest \\
\hline Sequential & Planning and Scheduling & Hierarchy & \\
\hline $\begin{array}{l}\text { Compatible- } \\
\text { reciprocal }\end{array}$ & $\begin{array}{l}\text { Self-organized } \\
\text { relationships and networks, } \\
\text { information } \\
\text { facilitate } \\
\text { adjustment }\end{array}$ & $\begin{array}{l}\text { Relationship and network } \\
\text { governance }\end{array}$ & 个 \\
\hline $\begin{array}{l}\text { Contentious- } \\
\text { reciprocal }\end{array}$ & $\begin{array}{l}\text { Organized business } \\
\text { ecosystem to facilitate } \\
\text { mutual adjustment based } \\
\text { on ecosystem-level } \\
\text { outcomes }\end{array}$ & Real or virtual hierarchy & Highest \\
\hline
\end{tabular}


governance. This is the second costliest workflow interdependence to coordinate.

Contentious-reciprocal

workflow

interdependence is coordinated by the organization of mutual adjustment for delivering ecosystem level outcomes. The cost of coordination for this type of interdependence is the highest. It is governed by real or virtual integration of the fragmented supply chain. Contentious-reciprocal interdependence governance can be done by restructuring business ecosystems into virtually integrated organizations using alliance forms of contracts that combine the fragmented network into a single "macrofirm" (Dioguardi, 1983).

In the case of the short sea logistics ecosystem, a number of contentious-reciprocal interdependencies led to conflicting sub goals of different actors, and these led to high coordination costs in the overall business ecosystem. The contentious-reciprocal workflow interdependencies that we analyzed were the costliest to coordinate. We earlier suggested a hierarchy for workflow interdependence analysis of business ecosystems, starting with contentiousreciprocal interdependencies, and then compatiblereciprocal, sequential, and pooled interdependence. The reason for this hierarchy is that the costliest coordination also generates the biggest lock-in effects, whose unlocking can provide great business ecosystem cost reduction. Our analysis of the short sea shipping case suggests that great cost reduction can be created through unlocking contentious-reciprocal interdependencies by appropriately aligned workflow governance.

This kind of result, all too common in complex long-term projects, can be explained by misalignments within business ecosystems and industry fragmentation - both of which evolve naturally over time in mature, fragmented markets as actors' goals differ and local optimization efforts lead inexorably to sub optimization of the overall business ecosystem. Enhanced governance mechanisms can include alliances and other means to alter actors' identities and relationships; and simulation, visualization, co-creation and marketmaking ICT tools can help resolve conflicts between different actors and their activities. Done correctly, virtual integration creates life-cycle long, system-wide economies of scale and realigns the activities of actors so they are not contentious, but rather are aligned towards a common system goal.

Further research could clarify the application of integral and modular system governance. For reciprocal interdependence, work is not suited for modularization, because of the need for adaptive coordination between workflows. Further research could investigate how reciprocal interdependence workflows could be managed by new work practices that are integral, but virtual, such as distributed work, and networks. For sequential and pooled interdependence, work can be broken up into modules, and done independently, as long as work delivers specified outputs on time. As work evolves, task interdependence changes, and future research could study management of the dynamism of changing work and workflow interdependence.

Governance of business ecosystems is a promising area for future research. Ostrom's theories of how some quasi-public goods, which she terms "collective commons" can be partly selforganized suggest that rules can be institutionalized voluntarily in the system (Ostrom, 1990, 2010; Ostrom et al., 1999). Such a view challenges the traditional model of forceful intervention by system integrators or regulatory institutions, and suggests that institutions can take on the role of facilitators of self-organizing coordination by actors in the business ecosystem. Future research should explore what kinds of governance can be used for self-organizing workflow coordination, and under which conditions it is suitable to apply it. Future research could also use our framework to develop business ecosystem optimization models.

Our framework keeps the focus on efficiency over the life-cycle of the project. We propose that constantly monitoring the project's progress can enable system integrators to adapt their governance modes to realign the ecosystem with changing realword conditions over time. Sustainable systemic performance improvements can be achieved by connecting the performance measurement of the project's progress to the ecosystem (Sundholm, Lepech, and Wikström, 2015). Future research should expand the analysis of workflows to identify projects that cover larger parts of the ecosystem (ports, cargo containers, export industries) and to identify the overall benefit of maximizing ecosystem efficiency. 
Future research could add much value by studying how governmental, social and culturalcognitive institutions in large mega-projects (Jooste, Levitt, and Scott, 2011) relate to the governance of workflow interdependence in business ecosystems.

\section{References}

Aalst W van der. 2000. Loosely coupled interorganizational workflows: modeling and analyzing workflows crossing organizational boundaries. Information \& Management 37(2): 6775.

Bailey DE, Leonardi PM, Chong J. 2010. Minding the Gaps: Understanding Technology Interdependence and Coordination in Knowledge Work. Organization Science 21(3): 713-730.

Barki H, Pinsonneault A. 2005. A model of organizational integration, implementation effort, and performance. Organization Science 16(2): 165179.

Barley SR. 1996. Technicians in the workplace: Ethnographic evidence for bringing work into organization studies. Administrative Science Quarterly 41(3): 404-441.

Chinowsky, P. (2011). Engineering project organization: defining a line of inquiry and a path forward. Engineering Project Organization Journal, 1(1), 3-10. doi:10.1080/21573727.2010.549611

Clarysse B, Wright M, Bruneel J, Mahajan A. 2014. Creating value in ecosystems: Crossing the chasm between knowledge and business ecosystems. Research Policy 43(7): 1164-1176.

Coget J-F. 2009. Dialogical Inquiry: An Extension of Schein's Clinical Inquiry. The Journal of Applied Behavioral Science 45: 90-105.

Coghlan D. 2000. Interlevel dynamics in clinical inquiry. Journal of Organizational Change Management 13: 190-200.

Coghlan D. 2011. Action Research: Exploring Perspectives on a Philosophy of Practical Knowing. The Academy of Management Annals 5: 53-87.

Conger J a., Kanungo RN. 1988. The Empowerment Process: Integrating Theory and Practice. Academy of Management Review 13(3): 471-482.

Crowston K. 1997. A coordination theory approach to organizational process design. Organization Science 8(2): 157-175.

Dioguardi G. 1983. Macrofirms: Construction Firms for the Computer Age. Journal of Construction Engineering and Management 109(1): 13-24."
Dougherty, D., \& Dunne, D. D. (2011). Organizing Ecologies of Complex Innovation. Organization Science, 22(5), 1214-1223.

Dyer JH, Nobeoka K. 2000. Creating and managing a high-performance knowledge-sharing network: The Toyota case. Strategic Management Journal. John Wiley \& Sons, Inc. 21(3): 345-367.

Dyer JH, Singh H. 1998. The relational view: Cooperative strategy and sources of interorganizational competitive advantage. Academy of Management Review 23(4): 660-679.

Echols A, Tsai W. 2005. Niche and performance: The moderating role of network embeddedness. Strategic Management Journal 26(3): 219-238.

Fry LW, Slocum JW. 1984. Technology, Structure, and Workgroup Effectiveness: A Test of a Contingency Model. Academy of Management Journal 27(2): 221-246.

Georgakopoulos D, Hornick M, Sheth A. 1995. An overview of workflow management: From process modeling to workflow automation infrastructure. Distributed and Parallel Databases. Kluwer Academic Publishers 3(2): 119-153.

Goldratt EM. 1997. Critical Chain. America. North River Press, 8.

Gulati R, Puranam P, Tushman M. 2012. Metaorganization design: Rethinking design in interorganizational and community contexts. Strategic Management Journal 33(6): 571-586.

Gulati R, Singh H. 1998. The Architecture of Cooperation: Managing Coordination Costs and Appropriation Concerns in Strategic Alliances. Administrative Science Quarterly 43: 781-814.

Hagel J, Singer M. 1999. Unbundling the corporation. Harvard business review 77(2): 133.

Håkansson H, Ford D, Gadde L-E, Snehota I, Waluszewski A. 2009. Business in Networks. John Wiley \& Sons.

Heath C, Staudenmayer N. 2000. Coordination neglect: How lay theories of organizing complicate coordination in organizations. Research in Organizational Behavior 22: 153-191.

Henisz WJ, Levitt RE, Scott WR. 2012. Toward a unified theory of project governance: economic, sociological and psychological supports for relational contracting. Engineering Project Organization Journal 2(1-2): 37-55.

Hickson DJ, Pugh DS, Pheysey DC. 1969. Operations Technology and Organization Structure: An Empirical Reappraisal. Administrative Science Quarterly 14(3): 378-397.

Holm DB, Eriksson K, Johanson J. 1996. Business Networks and Cooperation in International Business Relationships. Journal of International Business Studies 27(4): 1033-1053. 
Jacobides MG, Knudsen T, Augier M. 2006. Benefiting from innovation: Value creation, value appropriation and the role of industry architectures. Research Policy 35: 1200-1221.

Jooste SF, Levitt R, Scott D. 2011. Beyond 'one size fits all': how local conditions shape PPP-enabling field development. Engineering Project Organization Journal 1(1): 11-25.

Katz ML, Shapiro C. 1994. Systems Competition and Network Effects. Journal of Economic Perspectives 8(2): 93-115.

Kim K, Paulson BC. 2003. Agent-Based Compensatory Negotiation Methodology to Facilitate Distributed Coordination of Project Schedule Changes. Journal of Computing in Civil Engineering 17(1): 10-18.

Larsson R, Bowen DE. 1989. Organization and Customer: Managing Design and Coordination of Services. Academy of Management Review 14(2): 213-233.

Lawrence PR, Lorsch JW. 1967. Differentiation and Integration in Complex Organizations. Administrative Science Quarterly. Sage Publications, Inc. on behalf of the Johnson Graduate School of Management, Cornell University 12(1): 1-47.

Levitt RE. 2015. An extended framework for coordinating interdependent tasks in a project or functional ecosystem.

Mäkinen SJ, Dedehayir O. 2012. Business ecosystem evolution and strategic considerations: A literature review. In 2012 18th International Conference on Engineering, Technology and Innovation, ICE 2012 - Conference Proceedings.

Moore JF. 1996. The death of competition: leadership and strategy in the age of business eco-systems. Harper Business.

Normann R, Ramírez R. 1993. From value chain to value constellation: designing interactive strategy. Harvard Business Review 71(4): 65-77.

Ostrom E. 1990. Governing the Commons. The Evolution of Institutions for Collective Action. Cambridge University Press: Cambridge.

Ostrom E. 2010. Beyond Markets and States: Polycentric Governance of Complex Economic Systems. American Economic Review 100(3): 641672.

Ostrom E, Burger J, Field CB, Norgaard RB, Policansky D. 1999. Revisiting the commons: local lessons, global challenges. Science 284(5412): 278-282.

Pisano GP, Teece DJ. 2007. How to capture value from innovation: Shaping intellectual property and industry architecture. California Management Review 50(1): 278-296.

Porter ME. 1980. Competitive Strategy: Techniques for Analyzing Industries and Competitors. The Free Press: New York.
Saavedra R, Earley PC, Van Dyne L. 1993. Complex interdependence in task-performing groups. Journal of Applied Psychology. American Psychological Association 78(1): 61-72.

Sakhrani, V., Chinowsky, P. S., \& Taylor, J. E. (2017). Grand Challenges in Engineering Project Organization. Engineering Project Organization Journal, 7(1), 15.

Sanchez R, Mahoney JT. 1996. Modularity, flexibility, and knowledge management in product and organization design. Strategic Management Journal. John Wiley \& Sons, Ltd. 17(S2): 63-76.

Santos, F. M., \& Eisenhardt, K. M. (2005). Organizational Boundaries and Theories of Organization. Organization Science, 16(5), 491-508.

Sarasvathy SD, Dew N. 2005. New market creation through transformation. Journal of Evolutionary Economics 15(5): 533-565.

Schein EH. 1993. Legitimating clinical research in the study of organizational culture. Journal of counseling \& development 71: 703-708.

Schein EH. 1995. Process consultation, action research and clinical inquiry: arethey the same? Journal of Managerial Psychology 10: 14-19.

Schein EH. 2008. From Brainwashing to Organization Therapy. Handbook of Organization Development : $1-15$.

Schön DA. 1995. Knowing-in-action: The New Scholarship Requires a New Epistemology. Change 27(6): 26-34.

Sheffer DA. 2011. Innovation in modular industries: Implementing energy-efficient innovations in US buildings. Stanford University.

Sheffer DA, Katila R, Levitt RE, Taylor JE. 2013. Innovation of Unique, Complex Products.

Shih, H.M. and Tseng, M.M., 1996. Workflow technology-based monitoring and control for business process and project management. International Journal of Project Management, 14(6), pp.373-378.

Smith R. P, Eppinger SD. 1997. A Predictive Model of Sequential Iteration in Engineering Design. Management Science 43(8): 1104-1120.

Soda G, Zaheer A. 2012. A network perspective on organizational architecture: performance effects of the interplay of formal and informal organization. Strategic Management Journal. John Wiley \& Sons, Ltd. 33(6): 751-771.

Sosa ME, Eppinger SD, Rowles CM. 2004. The Misalignment of Product Architecture and Organizational Structure in Complex Product Development. Management Science 50(12): 16741689. 
Stieglitz N, Heine K. 2007. Innovations and the role of complementarities in a strategic theory of the firm. Strategic Management Journal 28(1): 1-15.

Stinchcombe AL. 1985. Contracts as Hierarchical Documents. In Organization Theory and Project Management Administrating Uncertainty in Norwegian Offshore Oil, Stinchcombe AL, Heimer CA (eds). Norwegian University Press: 121-171.

Sundholm V, Lepech MD, Wikström K. 2015. The dynamic nature of governance structures for large investments - measurement and modeling, organizational fit, and lifecycle value. In EPOC 2015 Conference.

Teece DJ. 1986. Profiting from technological innovation: Implications for integration, collaboration, licensing and public policy. Research Policy 15: 286-305.

Thompson JD. 1967. Organizations in action: Social science bases of administration. University of Illinois.

Tracey, P., Phillips, N., \& Jarvis, O. (2011). Bridging Institutional Entrepreneurship and the Creation of New Organizational Forms: A Multilevel Model. Organization Science, 22(1), 60-80.

Tripathy A, Eppinger SD. 2013. Structuring work distribution for global product development organizations. Production and Operations Management 22(6): 1557-1575.

Tsvetkova A. 2014. Designing sustainable industrial ecosystems: the case of a biogas-for-traffic solution. Åbo Akademi University.

Vegt G Van Der, Vliert E Van De. 2002. Intragroup interdependence and effectiveness: Review and proposed directions for theory and practice. Journal of Managerial Psychology 17(1): 50-67.

Walsh, J. P., Meyer, A. D., \& Schoonhoven, C. B. (2006). A Future for Organization Theory: Living in and Living with Changing Organizations. Organization Science, 17(5), 657-671.

Zammuto, R. F., Griffith, T. L., Majchrzak, A., Dougherty, D. J., \& Faraj, S. (2007). Information technology and the changing fabric of organization. Organization Science, 18(5), 749-762.

Zajac EJ, Olsen CP, Studies M, Pacific SENS. 1993. From transaction cost to transactional value analysis: implications for the study of interorganizational strategies. Journal of Management Studies. Blackwell Publishing Ltd 30(1): 131-145.

Zott C, Amit R. 2010. Business Model Design: An Activity System Perspective. Long Range Planning 43(2-3): 216-226. 